No. 1,568.- " Chemical and Physical Analyses of Phosphoric Steel." By Alexander Lyman Holley, M. Inst. C.E.

Phosphoric steel may be defined as steel in which the principal hardening and body-giving ingredient is phosphorus, and in which the amount of this element exceeds that of the carbon. Manganese in large proportion is used in the manufacture of this steel in order to improve its malleability, and this element is also believed to modify the cold-shortening effect of phosphorus. This manufacture is covered in the United States by letters patent to Tessé du Motay, dated May 5th, 1874, and to Fred. J. Slade, dated December 14 th, 1875 . Steel containing about $0 \cdot 20$ of phosphorus, 0.15 of carbon, and 0.75 of manganese, has, for several years, been manufactured at Terrenoire, in France, and has been successfully used for rails. The same ingredients in other proportions have also been employed to a limited extent for different purposes. An abstract of various published experiments on this Terrenoire steel, and a comparison of its chemical and physical tests with those of ordinary steels, are appended to this Paper.

The following experiments, conducted by the Author at the Norway Iron Works in Boston, U.S., in the summer of 1877, were intended to be a more complete guide, both to steel-makers and to constructors, in the use of steels of this kind; to indicate, by a more elaborate comparison of chemical and physical results, how far and for what purposes cheap materials, such as old iron rails, may be introduced into new structural steels.

In some of the charges referred to, a flux was employed, which duplicate analyses and all physical tests, both at these and at other works where it was used, proved to have had no obvious effest upon the product; therefore these considerations need not be embarrassed by farther reference to the flux.

The steel was all made in the same open-hearth furnace. The operations of selecting, weighing, charging, melting, and working the ingredients, of casting the product, and of heating, rolling, and testing the ingots experimented upon, were witnessed either by the Author's assistant or by himself; and most of these operations were witnessed and noted by them both. The analyses given are averages of these by Dr. $\mathrm{O}$. Wuch, of Pittsburgh, and 
by Dr. A. Wendel, of Troy. In most cases they were nearly coincident; in a few cases where there was considerable discrepancy, the same sample was analysed again, but the results being nearly as before, it was concluded that there was a difference in the borings from the same bar.

Ingots from various charges were also sent to the Albany and Rensselaer Iron and Steel Works at Troy, for two reasons: 1st. Having been concerned in the establishment and conduct of the system of physical tests uniformly practised there for above ten years, the Author had a peculiar confidence in its results; 2nd. The rolling of fine, low steels having been long practised at those works, it was felt that the results would confirm the equally expert practice at the Norway Iron Works.

\section{The Materials Used.}

The analyses of these materials are given in Table 1 .

\begin{tabular}{|c|c|c|c|c|c|c|c|c|}
\hline \multicolumn{9}{|c|}{ "Fayette" Pig. } \\
\hline Silicon. & . & . & * & . & • & & & $1 \cdot 310$ \\
\hline Sulphur & . & : & . & . & & & & $0 \cdot 005$ \\
\hline Phosphorus & . & . & - & . & . & & & $0 \cdot 148$ \\
\hline Manganese & . & . & . & . & . & & & 0.647 \\
\hline
\end{tabular}

Old iron rails used in charges Nos. 596, 598, 600, 601, 602, $603,604,634,635,636,637$.

Carbon. . . . . . . . . . . . . . . . 0.080

Silicon. . . . . . . . . . . . . . . . 0.179

Sulphur . . . . . . . . . . . . . . . $0 \cdot 170$

Phosphorus . . . . . . . . . . . . . . 0.498

Manganese . . . . . . . . . . . . . . 0.088

Round bar (1: in.) made from a piece of the above old rails.

Phosphorus $0 \cdot 334$

Old iron rails used in charges Nos. 611 and 612 . Phosphorus

Puddled bar used in charges Nos. 596 and 598.

Silicon. . . . . . . . . . . . . . . . 0.032

Sulphur . . . . . . . . . . . . . . . 0.013

Phosphorus . . . . . . . . . . . . 0.084 
Steel scrap used in charges Nos. 600, 601, 602, 603, 604. Phosphorus . . . . . . . . . . . 0.079

Steel scrap used in charges Nos, 611 and 612. Phosphorus . . . . . . . . . . . . 0086

\section{Spiegeleisen.}

Phosphorus . . . . . . . . . . . . . . 0.075

Manganese . . . . . . . . . . . . . . $16 \cdot 870$

Ferro Manganese.

Manganese . . . . . . . . . . . . . . $63 \cdot 52$

The pig was all taken from one pile, and six pieces were selected from different parts of the pile for analysis. The old iron rails for all the charges, excepting Nos. 611 and 612, were chosen from the same pile, and they were of the same make and quality. Sufficient rails to furnish a whole series of experiments were cut up and thoroughly mixed, and not less than a dozen specimens from all parts of the pile were taken for analysis. Three pieces of old rail ( $4 \frac{1}{2}$ inches high, weighing 64 lbs. per yard) were placed on supports 28 inches apart, and subjected to blows from a 1,700-1b. drop. The first specimen broke under a 2 -feet blow; the second stood an 18-inch blow, deflecting slightly, and then broke under a 1-foot blow; the third broke under a 2-feet blow.

The puddled bar used in charges 596 and 598 was tested by bending cold to $1 \frac{1}{2}$-inch radius without fracture. The steel scrap employed was taken from a bin which is reserved for the scrap of certain charges made out of uniform materials for the same use, viz., horse-nail plate. Drillings for analysis were obtained from nearly a dozen specimens. The spiegeleisen and the ferro-manganese were sampled for analysis with equal care.

It will be observed that the pig-iron, which was about 19 per cent. of the charge, was of fair quality; that the old rails, which constituted above 57 per cent., were very bad; and that the scrap, about 20 per cent., was good. Also that the materials forming the bath must have been nearly uniform. Hence it cannot be objected to the experiments that any peculiarity in the results is due to unknown conditions and ingredients. 
The details of the charges are given in Table 2.

Thbie 2.-Abstract of Charges.

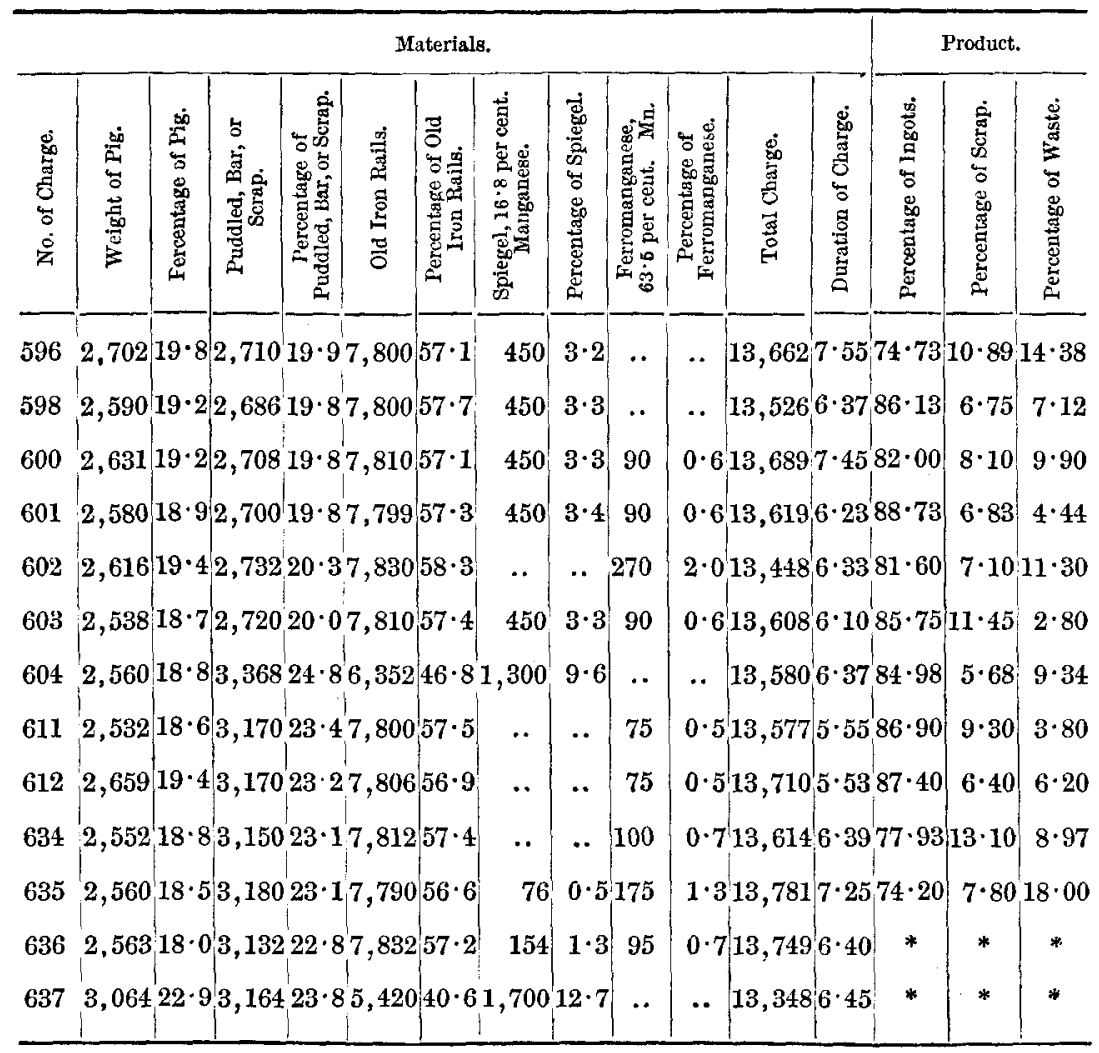

* Noтe.-The metal remaining in the furnace from charge 636 ran out with 637, giving 13,817 Ibs. of ingote.

They were, however, formulated as shown in Table 3, which has been selected as an illustration. 
CHEMICAL AND PHYSICAL ANALYSES OF PHOSPHORIC STEEL. 225

Table 3.-Charge 611. May 24th, 1877.

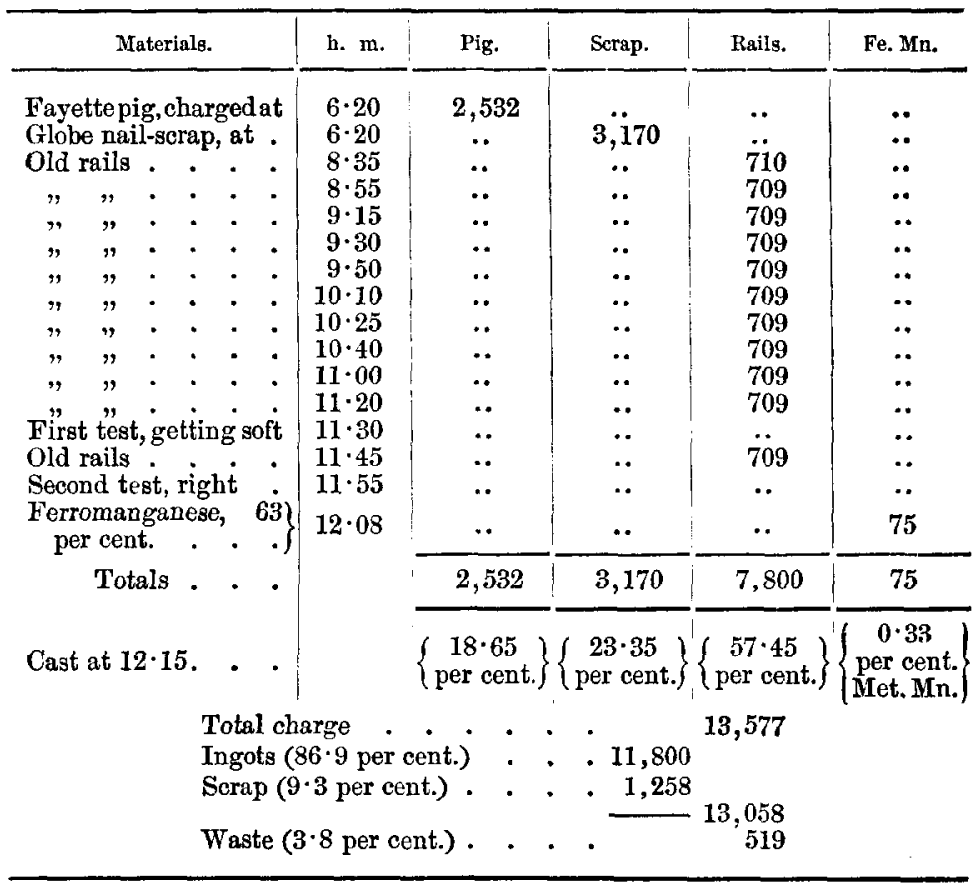

Table 4.-Anahtsts and Average Strength of Finished Product.

\begin{tabular}{l|c|c|c|c|c|c|c|c|c|c|c|c|c|}
\hline No. of Charge. & 596. & 598. & 600. & 601. & 602. & 603. & 604. & 611. & 612. & 634. & 635. & 636. & 637. \\
\hline
\end{tabular}

Carbon . $0 \cdot 230,0 \cdot 2200 \cdot 1930 \cdot 2200 \cdot 1720 \cdot 2300 \cdot 4500 \cdot 1210 \cdot 1230 \cdot 1100 \cdot 1240 \cdot 1030 \cdot 430$ Silicon. $\quad 0.0430 .0340 .0380 \cdot 0460.0300 \cdot 0420.0400 .0130 .0040 .0560 .0050 .0170 .023$ Sulphur $\quad 0 \cdot 1780 \cdot 1090 \cdot 1030 \cdot 0990 \cdot 1140 \cdot 0800 \cdot 0880 \cdot 0540 \cdot 0870 \cdot 0780 \cdot 0950 \cdot 0890.053$ Phosphorus $0 \cdot 3830 \cdot 3410 \cdot 3340 \cdot 3320 \cdot 3600 \cdot 2970 \cdot 2880 \cdot 2410 \cdot 2990 \cdot 2710 \cdot 2540 \cdot 2930 \cdot 255$ Manganese $0.5960 .4840 .4310 \cdot 6890 \cdot 9570 \cdot 6720 \cdot 6300 \cdot 3900 \cdot 3700 \cdot 5020 \cdot 6270.5620 .693$

Average Strength per Square Ixch.

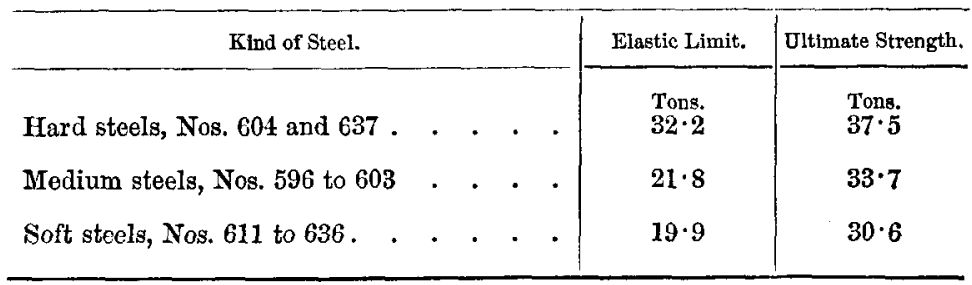

[1877-78. N.S. $]$

Downloaded by [ University of Liverpool] on [16/09/16]. Copyright (C ICE Publishing, all rights reserved. 


\section{Results of Roling the Ingots.}

Ingots from all the charges were rolled at the Norway Ir Works, and ingots from some of the charges were also rolled the Albany and Rensselaer Iron and Steel Works at Troy, before stated. The Terrenoire experience with phosphoric ste had taught, that the working of such steel hot was almost important a factor in determining its value as its physical qualiti. when cold. However well a steel may be adapted to certain use in consideration of its cheapness, this consideration ceases to exi; if the metal can only be nursed into shape by numerous operation: and at the risk of a large percentage of cracked and imperfect bar For this reason the heating and rolling experiments were carefull: conducted and watched.

At the Norway works, high and rapid heats were given in som. cases, not for the purpose of showing any charge at a disadvan tage, but to get at all the facts. Other ingots from the samt charges were given the benefit of a cool furnace, slow heating, anc light hammering previous to rolling. Everything that could be done to give the steel fair play was done at the Norway works, except one thing which could not be helped, and which counted against all the charges alike. The rolls were adapted to iron piles; their reduction was too rapid for steel-about 25 per cent. in each of the first few grooves-and some of those grooves were gothic; this was peculiarly bad for the early passes of ingots, because, while it drew two corners under compression, it left two corners of a metal which was as yet porous and weak to be stretched without compression. Hence a steel like phosphoric steel, which is particularly weak and "cracky" at the comparatively high heat at which it enters the rolls, is pulled apart by gothic grooves, while box grooves, holding up all the corners, would make sound work. When the piece gets cooler, more condensed and stronger, gothic grooves, by reducing four sides at once, do more work in a given length of rolls.

The ingots were only 6 inches square at the large end, and were rather long for their thickness. This, together with the rapid reductions, cannot be said to have given a phosphoric steel a fair chance. Every expert knows that of steel which has a tendency to crack, large ingots, say 12 or 14 inches square, carefully bloomed and reheated, may make sound bars, when small ingots, rapidly reduced, might fail altogether. The 6-inch ingots were bottom-cast, and were probably as sound as ingots of this size conld have been made. 
Charge 596.-The lower half of an ingot was heated in a very hot furnace, from which a charge of iron scrap-balls had just been drawn. It cracked nearly clear across in four or five places in the first pass, and went to pieces in three passes. The other half of the ingot was then charged into a cooler furnace, heated three quarters of an hour to a bright red, but not a yellow heat, and carefully reduced about 1 inch all over under a hammer suitable for such work. The bloom showed several bad cracks in the corners. Upon being carefully reheated to a bright red-a low heat for soft steel-it was rolled; it cracked nearly through at the third pass, and fell apart when reduced to $2 \frac{1}{2}$ inches square. This was not considered marketable steel. Another ingot of this charge was heated nearly three hours and carefully hammered, with no visible cracks; it was then carefully reheated and rolled into a very bad 2 -inch round.

In this oharge the percentage of sulphur was nearly $0 \cdot 18$, and that of phosphorus was above $0 \cdot 38$; but the percentage of manganese was not so high as in heats which rolled much better. Why the red-shortening sulphur was less worked out of this than out of the other charges it is difficult to say. From previous knowledge of the effects of phosphorus and sulphur, it would be inferred that this charge would go to pieces in the rolls.

Charge 598.-The top half of an ingot was charged into a furnace heated to about a proper temperature for steel for one hour and a quarter, and carefully hammered to about 5 inches square with very little cracking. At a low, yellow reheat, suitable for low steel, it was rolled to $3 \frac{1}{2}$ inches square, and cracked rather badly on the edges. Again heated to a bright red, this bar was finished to an apparently pretty sound 2-inch round, but when cold it showed many surface flaws. A piece of the 2-inch round was heated fifteen minutes, and rolled to 2 inches by $\frac{5}{8}$ inch; this was again heated and rolled to $1 \frac{1}{2}$ inch by $\frac{1}{4}$ inch. The two last-mentioned trains of rolls were well adapted to steel, and were constantly rolling steel. The small bars were not quite perfect; they would not have passed as merchantable steel, except perhaps for such purpose as sleigh shoes. The original cracks were reduced at each re-rolling, but were all still visible. The bottom half of the same ingot was heated to a red heat, suitable for a tool steel, and rolled direct. It cracked a little less than the hammered bloom last mentioned. A second ingot of this charge was heated nearly three hours, but to a bright yellow heat; after being hammered without cracking, it was reheated over half an hour, and rolled, with almost exactly the results previously mentioned. 
The analysis shows no reason why this steel should be more malleable than that of charge 596, except that it has only about 60 per cent. as much sulphur. Although the heat was high, its gradual application undoubtedly improved the rolling of the bars.

Charge 600.-The lower end of an ingot was heated forty minutes to a bright red, nearly yellow. It was rolled direct, and cracked very badly, nearly parting in six or eight places. The top half of the same ingot, heated just an hour in a temperature suitable for rather high steel, was hammered to a nearly sound 5 to $5 \frac{1}{2}$-inch bloom. This, upon a slightly higher reheat, rolled, despite its cracking, some in the first gothic passes, to a good-looking but not perfect 2 -inch round. A piece of the 2-inch round was rolled, in the same manner as charge 598 , to a $1 \frac{1}{2}$-inch by $\frac{1}{4}$-inch bar, which was pretty sound, but upon inspection it still showed traces of the cracks produced by the gothic grooves. Another ingot of this charge, heated nearly three hours to a bright yellow, hammered and rolled, made bars which were a little more sound. This charge (600) was nearly identical chemically with 598 , so that the remarks regarding the last-named charge will apply to it.

Charge 601.-The ingots, upon fracture, appeared more solid than the previous ones. The bottom half of an ingot, at a suitable bright red heat, was rolled directly into a $1 \frac{1}{4}$-inch billet, which looked well, but was not quito sound. It cracked almost as badly as 600 had done in the first three gothic passes, but the cracks "pulled out" as the piece was reduced. The top half of the same ingot was heated one hour and thirteen minutes in a cool furnace. It was "nursed" by frequent turning, and hammered to an apparently perfect 5 -inch bloom. This was carefully heated, and rolled to a rather better 2 -inch round than either of the previous ones. It cracked about $\frac{1}{2}$ inch deep in the first gothic passes, but the cracks pulled out in the round. Upon close inspection when cold, however, a perfectly sound length of 4 feet could not be cut out of a bar about 15 feet long. Another ingot of this charge, heated three hours to a bright yellow, hammered and rolled, gave no better results.

The larger percentage of manganese in this charge may probably account for its somewhat better performance.

Charge 602.- The two halves of an ingot were charged into a cool furnace. The lower end was one hour and thirty-five minutes heating, and was drawn at a bright red heat suitable for such steel. It cracked, in direct rolling, slightly less than the best 
previous charge. The deepest crack was about $\frac{1}{2}$ inch. The resulting $1 \frac{1}{8}$-inch billet appeared to be quite sound, but upon inspection when cold some imperfections were found upon the corners. The upper end of the ingot having been heated about one hour and three quarters was hammered to a 5-inch bloom, which showed no cracks. After about ten minutes' reheating to a bright red, slightly lower than the temperature of the previous heats, this bloom was rolled to a rather better 2-inch round than the preceding ones; but upon inspection when cold it showed some small remnants of the cracks which the gothic grooves had made. Another ingot of this charge, heated three hours to a bright yellow, hammered and rolled, produced rather sounder bars than any of the previous charges.

The intention was, in making this charge, to bring the carbon down to about 0.12 per cent., and the manganese to 0.75 per cent.; but this being the first experiment with low carbon phosphoric steel, the fear of a chill in the furnace induced the furnaceman to tap the charge before the carbon, manganese, and possibly some other impurities, were properly reduced. The good effect of the manganese, however, upon the malleability of the metal, is obvious but not conspicuous.

Charge 603.- The two halves of an ingot were heated one hour and ten minutes. The bottom end was drawn at the heat of $602^{\circ}$, and rolled with the same results into a $1 \frac{1}{\mathrm{~g}}$-inch billet; it, however, had four light reheats before it was finished, on account of the failure of the breaking-pieces over the rolls. The other end of the ingot was hammered with slight cracking and rolled down, in the same manner as the previous ingots, to almost perfect bars. Charges 602 and 603 worked hot almost exactly alike; if there was any difference, 602 was the better charge. Another ingot of this charge was heated to a bright yellow, hammered and rolled, with almost exactly the preceding results. This charge was slightly lower in phosphorus than the preceding one, and it had a good percentage of manganese.

Charges 602 and 603, rolled at Troy.-The first report of Mr. R. W. Hunt, General Superintendent of the Albany and Rensselaer Iron and Steel Works, is as follows:- "Two of the ingots, marked 602 and 603 , were heated very carefully to a moderate heat, and then broken down in an 18-inch train to $2 \frac{1}{4}$-inch billets. No. 603 cracked more in the edges than 602 . The billets were then washheated and rolled into 1 -inch square bars in a 9-inch train. The bars from both were imperfect on the edges, showing slivery cracks at various points, those on 603 being largest." 
Mr. Hunt's second report is as follows:- "The rolling of the other two ingots, marked 602 and 603 , into 2 -inch square bars gave the following results: The heat being a low and very careful one, 602 made a much better bar than 603 , but had several cracks on the edges ; 603 cracked very badly, and hardly held together while going through the first passes."

Charge 604. - This was intended to be a hard charge suitable for tools. An ingot was heated nearly three hours, and hammered without cracking. It was then reheated about fifteen minutes and rolled; it cracked rather badly in the gothic grooves, and made an imperfect, but not very bad 2-inch round. A second ingot of the same charge beated at the same time, and rolled directly without hammering, cracked badly in the first gothic groove, and made an inferior $1 \frac{1}{8}$-inch square bar. A third ingot heated about three hours to a bright yellow, was hammered, very carefully reheated and rolled into a bar nearly similar to that made from charge 600 . Another ingot was heated two hours, hammered to about $4 \frac{1}{2}$-inch square (a little smaller than the previous ones), and reheated and rolled with about the preceding results. Although in this charge the percentage of carbon was $0 \cdot 45$, there is no reason why it should not have rolled well at a moderate heat, except that both phosphorus and carbon were rather in excess, and that they do not work well together, either hot or cold. Sulphur and silicon were very low; the percentage of phosphorus was less than in the preceding charges, and manganese was in good quantity.

Other ingots from charges Nos. 600, 601, 602, and 603 were afterwards heated about two hours to a low yellow, and carefully hammered. 'The blooms were then reheated and rolled as before, and they all made slightly better bars than the previous ones, except that No. 601 did not roll quite as well.

Charge 611.-Four ingots of this charge were heated two hours and twelve minutes to a bright yellow, and were rolled without hammering into about the same quantity of bars as charges 600 and 601. Another ingot heated a little less, but faster, made a slightly better bar.

Charge 612 was heated with charge 611 to the same temperature, and gave nearly the same result. Both of these charges were low in carbon $(0 \cdot 12)$; they were also poor in manganese $(0 \cdot 37$ to $0 \cdot 39)$, considering the phosphorus they contained $(0.24$ to 0.29$)$ and their low carbon.

The comparatively good quality of charges 611 and 612 may be partly traced to the high heat of the bath and the rapid melting 
of the old rails, which were put into the furnace in small quantities and at a high temperature, and were almost immediately dissolved. This result cannot be specifically explained, but it confirms those at Terrenoire, where the object is to produce the phosphoric steel at the highest heat attainable and in the shortest time.

Charge 634.-An ingot of this charge was heated slowly to a low yellow, and hammered to 5 inches square. The bloom was then reheated, along with iron piles, in a hot furnace to a medium yellow, and rolled into as good a 2-inch round bar as had been previously made. On another day two ingots of this charge were heated to a low yellow, and rolled direct, one into a 2 -inch round and the other into a bar $2 \frac{1}{2}$ by $2 \frac{5}{3}$ inches. There were a very few small cracks from the gothic grooves, and both bars were merchantable but not absolutely perfect. Although these bars had the average quality of surface for common uses, they could not be finished, without objectionable flaws, in the lathe or planer. A piece of 2 -inch round from the firstmentioned bar was rolled at two heats into a bar $\frac{3}{4}$ by $\frac{3}{16}$ inch, and made into bars which were pronounced merchantable by all the experts who examined them. Pieces of the second and third ingots were also rolled at similar heats into equally good bars. The somewhat smaller percentage of phosphorus may account for the better rolling of this charge. It should also be remarked that the temperature of the bath was nearly as high as in the case of charges 611 and 612 .

Charge 635.-An ingot from this charge was heated, hammered, and rolled, precisely like 634 , except that the reheat was a little higher. The 2 -inch round bar from 635 was slightly better than the one from 634, and it was a merchantable bar. Some pieces of the 2-inch round were rolled to $\frac{3}{4}$ by $\frac{3}{16}$ inch, and made mer. chantable bars. Two more ingots of this charge were rolled direct, without hammering, at a low yellow heat, into two bars; one into a 2 -inch round and the other into a flat, both bars being a trifle smoother than the bars of 634 . A piece of the 2 -inch round was rolled into a $1 \frac{1}{2}$ by $\frac{3}{8}$ inch merchantable bar. The remarks about charge 634 apply to 635 , except that the higher percentage of manganese $(0.62$ against 0.50$)$ should improve the rolling.

Charge 636.-An ingot of this charge was heated slowly to a low jellow, hammered, reheated and rolled. The reheat was a bright yellow, much hotter than 634 and 635 , and the 2 -inch round was very imperfect. A piece of the 2-inch round was rolled to $1 \frac{1}{4}$ to $\frac{3}{8}$ inch, and this was rolled into a merchantable bar $\frac{3}{4}$ by $\frac{3}{16}$ inch. Another ingot of this charge was rolled, without hammering, at a jellow heat, and was cracked badly in the gothic grooves; it made 
an imperfect 2-inch fround, a short sound piece of which was rolled into a merchantable bar $1 \frac{1}{2}$ by $\frac{3}{8}$ inch.

Charges 634,635 , and 636 were substantially alike chemically, but did not roll so nearly alike as three ingots of the same charge would ordinarily roll.

Charge 637.-An ingot of this charge, rolled without hammering, at a low yellow heat, cracked badly in the first gothic groove, one crack going nearly through. It made a fair but imperfect 2-inch round, the large crack remaining. A short sound piece of this bar was rolled into a merchantable bar $1 \frac{1}{2}$ by $\frac{3}{8}$ inch. It is probable that tho first heat given to this ingot was too great for a steel containing nearly 0.50 per cent. of carbon.

Charges 634, 635, 636, and 637, rolled at Troy.-Mr. Hunt's report is as follows:--"We rolled the ingots into 2 by $1_{2} \frac{1}{2}$ bars.

" 634 rolled quite well, having a few cracks at one end on one edge.

" 635 rolled better than 634 .

" 636 cracked on all four edges. The cracks were 'dry.'

" 637 cracked very badly on all the edges. The steel seemed ' dry'; it wanted consistency.

"The heats on all these pieces were mild, and as nearly alike as possible."

Conclusions about Rolling.-The following Table 5 is intended to give the order of merit of all the charges (excepting the hard ones, 604 and 637 , which could not be properly considered along with the soft charges), in respect of their capacity to stand heat and reduction.

All the charges, excepting perhaps 596 and 598, showed a capacity to make merchantable bars of simple section, suitable for many purposes, even when rolled from small ingots. Probably all the steel, without exception, could have been worked up to advantage if the ingots had been, say 12 inches square, charged hot from the moulds, very slowly heated and carefully bloomed.

Table 5.-Order of Merit as to Malleability.

\begin{tabular}{l|c|c|c|c|c|c|c|c|c|c|c}
\hline No. of charge. & 635 & 634 & 602 & 603 & 600 & 611 & 612 & 601 & 636 & 598 & 596 \\
\hline Order of merit. & 1 & 2 & 3 & 4 & 5 & 6 & 6 & 7 & 8 & 9 & 10 \\
\hline
\end{tabular}

Mechanical Tests at Troy.-The bars were all $1 \frac{1}{2}$ inch by $\frac{3}{8}$ inch. They were treated precisely in the manner employed for all 
Bessemer steel test-bars at the Albany and Rensselaer Iron and Steel Works, by experts who have made many thousands of similar tests. Mr. Shields, who has the direction of the testing department, has furnished Tables 6, 7, and 8, which give two series of experiments. The diagrams (Tables 7 and 8) represent the specimens after treatment.

These tests are chiefly valuable as showing the comparative ductility of the steels. In comparing them with the ductility tests of the same steels made at the Stevens Institute, it will be observed that the results agree very closely. They also give the expert an idea of the general quality of the steels.

Table 6.-Mechanicat Tests at Troy.

Note.-In the "grade" referred to $I$ is extreme hard and V extreme soft, within the ordinary Bessemer range.

\begin{tabular}{|c|c|c|c|c|c|c|c|c|c|c|c|c|c|c|}
\hline Charge & . . & 596 & 598 & 600 & 601 & 602 & 603 & 604 & 611 & 612 & 634 & 635 & 636 & 637 \\
\hline Grade & . . & III & $\mathrm{ILI} \frac{\mathrm{I}}{\mathrm{Z}}$ & III $\frac{3}{4}$ & III & $\mathrm{II}_{4}^{3}$ & IIII $\frac{1}{2}$ & $\mathrm{II}_{4}^{1}$ & V & V & $\mathbf{V}$ & $I V \frac{1}{2}$ & $\mathrm{IV}_{\frac{3}{4}}$ & $\mathrm{II}_{\frac{3}{4}}^{3}$ \\
\hline
\end{tabular}

Tabue 7.-Mechantal Tests at Troy.-First Trial.

Cold bend Annealed. Cold bend Hardened. Cold bend Annealcd. Cold bend Hardened.
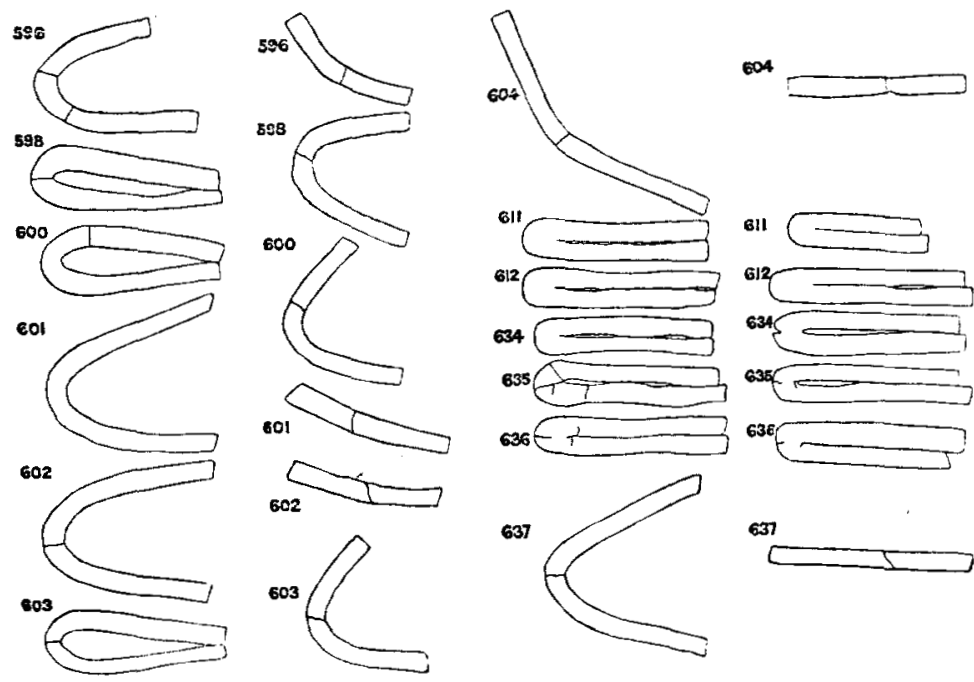

637

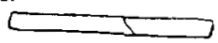


Table 8.-Mechaxioal Tests at Trot.-Second Trial.

Cold bend Annealed.

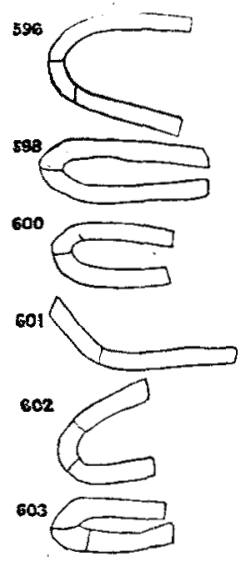

Cold bend Hardene

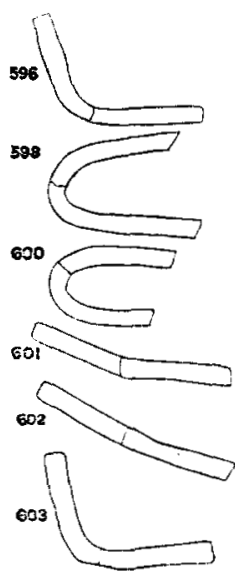

Cold bend Annealed.

Cold bend Hardened.

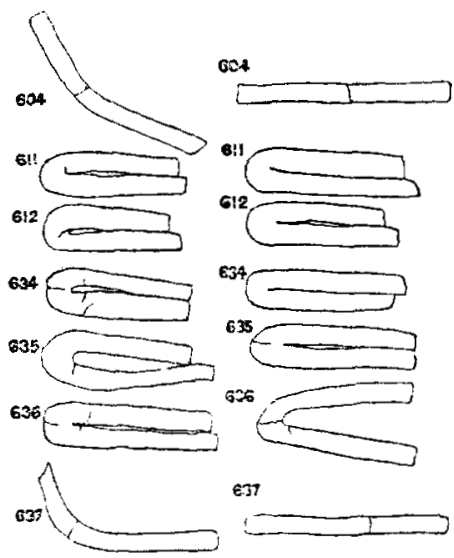

REMarks.

604.-Broke without bending after temper. It is the only one that showed any hardness after temper when cut with a file; it showed nearly as much cold-shortness as 596,601, and 602. All the tests showed some cold-shortness, 596, 601, and 602 much more than the others.

611.-Bent double without any sign of fracture; did not temper in the slightest degree either at a red or high yellow heat; bent as well after temper as before, and made a pretty fair weld.

612.-Bent double and showed no signs of hardening after tempering.

634.- Showed no signs of hardening after temper.

635 and 636 .-No harder than 634 , but uniform in tenacity.

637.- Showed a good deal of cold-shortness; metal which shows so little hardness should, after tempering, bend to a right angle.

\section{Character of Tools made from Hard Charge, No. 637.}

Mr. R. W. Hunt, Gen. Supt. of the Albany and Rensselaer Iron and Steel Works, Troy, reports as follows on chisels and turning tools. "The cold-chisels failed after several trials of tempering. The turning and planing tools stood better, but cannot be called good steel. They stood pretty well. You will observe that the bar rolled pretty seamy." 


\section{Mechanical Tests made at the Stevens Instrtute of TeChNOLOGY.}

These tests were made, and their results were tabulated, under the superintendence of Professor R. H. Thurston, at the mechanical laboratory of the Institute.

The soundest 4-feet length was cut out of one of the 2-inch round bars from each charge. The test specimens were turned from these 4-feet bars.

Table 10 has been condensed from all the tables received, for the purpose of bringing the important results into more convenient form for inspection. The order of merit given in the tables was made by Professor Thurston without any knowledge on his part of the chemical constituents of the steels. After his tests were made, it was deemed only fair to give him the carbon determinations before asking for an opinion on the relative qualities of the steels. His further statement regarding the positive and comparative qualities of the steels is appended. There were also furnished with these tables the diagrams made by Professor Thurston's autographic torsion-machine. This table also contains the results of tests made at the same place on wrought irons and steels of known grade, embracing the varieties of quality possessed by Nos. 596 to 637 .

Two tensional, two compressive, and three torsional tests were made on No. 596 to No. 637 steel, and the figures given in Table 10 are averages of these several tests. All tensional specimens were 0.798 inch in diameter (or $\frac{1}{2}$ square inch area), and 6 inches long. All torsional specimens were 0.625 inch in diameter and 1 inch long. All compression specimens were 0.50 inch in diameter and 2 inches long.

Elastic Limit in this table means the load at which the distortion, extension, torsion, or compression cease to be directly proportional to the applied stress. The elastic limits of all samples are such as to represent the stresses which can be borne continually without injury. Under the heading Strength-Elastic limit, and in the columns headed respectively tension, torsion, and compression, are given the actual stresses which strained the specimens to their elastic limits.

Under the heading Strength-Ultimate, the figures in the columns headed tension and torsion respectively, are the rupturing stresses of the specimens. In the column headed compression the figures are the stresses which caused a wedge of metal to be sheared off the specimen, or which bent it into a lump, the resistance increasing as the pressure increased. Professor Thurston, how- 


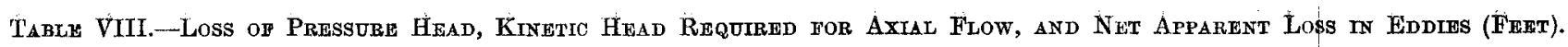

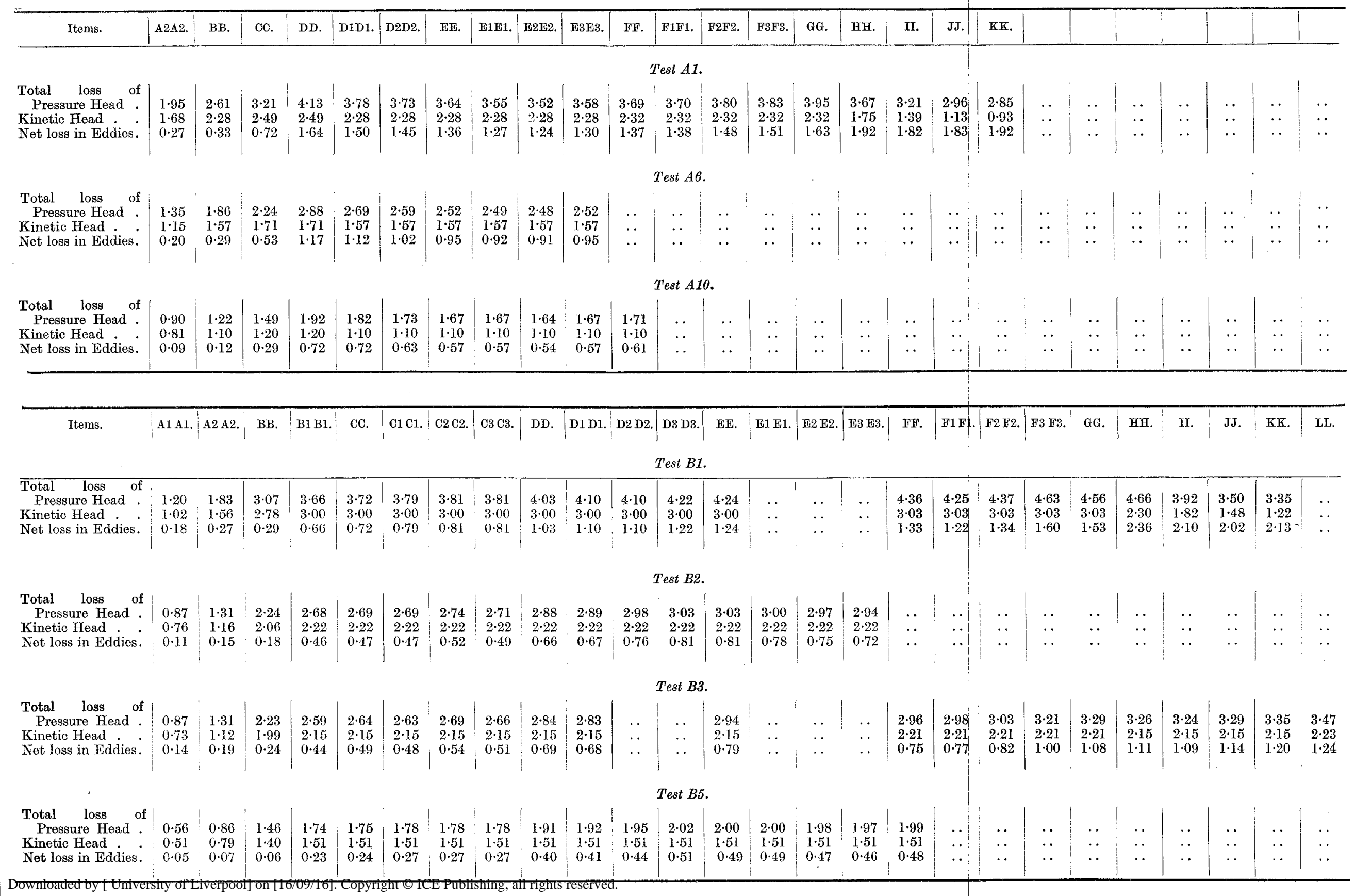


ever, does not consider that these figures represent the crushing strength of a material; he thinks that the strength which produces a bending sufficient to visibly roughen the surface of the specimen is more correctly the crushing resistance. Therefore the loads are given at which the compression specimen bent in the column headed bending points, and these are suggested as the crushing strength of the material tested.

Under the head of Resilience-Elastic Limit-Ultimate, are given respectively the foot-pounds of mechanical work expended in straining the specimens to their elastic limits, and in rupturing them. The resiliences at the "bending points" are suggested as the rupturing resiliences for compression. The Elastic limit resiliences were calculated by multiplying half the distortion, in feet, at the elastic limit by the stress in lbs. producing the distortion. The Ultimate resiliences were calculated from the areas of the diagrams representing the behaviour of the respective specimens. The automatically produced diagrams were used in the case of torsion; and plotted curves, having the applied stresses and their corresponding distortions for co-ordinates, giving the necessary data, were used in the cases of tension and compression.

Stiffness is understood to be the rate of distortion of a material, or the number of units of stress necessary to produce one unit of distortion. Within the elastic limit, the stiffness for tension is represented by the modulus of elasticity. 'The formula employed is : Load per square inch of cross section divided by the stretch per inch of length. For torsion the measure of stiffness used is the number of foot-pounds of stress necessary to produce one degree of distortion, the figures being obtained by dividing the moment representing the elastic limit by the angular measurement in degrees twisted through up to that elastic limit. For compression, the measure is similar to that for torsion, the figure coming from the division of the elastic limit by the distortion at this point. Beyond the elastic limit the stiffness has been measured by the amount of distortion produced in each specimen for a given stress. The stress for tension is taken at $30,000 \mathrm{lbs}$., as this is the greatest stress at which a correct extension was obtained for all specimens from No. 596 to No. 637. Similarly, in compression, the stiffness beyond the elastic limit is measured by the compression due to 14,000 lbs., the least " bending point" of the specimens. In torsion, the degrees of torsion produced by 285 foot-pounds of stress (the least borne by any of the specimens) are taken as a measure of stiffness beyond the elastic limit.

Ductility is represented by the maximum distortion which a 
material experiences before rupture, and the figures given under this head are simply the total elongations, correctly ascertained, in tension, and the maximum number of degrees of stretch in torsion. For compression, the figures represent the compression at the "bending points."

It is worthy of note that, in almost every tensional specimen, flaws existed in the fractured sections. In a large number of them the surfaces broke open over a considerable length, and in some instances the least diameter of the ruptured specimen was not that of the fractured section. There were, however, so many other mechanical tests that this behaviour of the tensional specimens does not affect the general result. The peculiarities of each tensional specimen are noted below :-

596-1st spec.-Flaw in fracture; surface uninjured.

2nd spec.-Surface very badly corrugated; least cliameter $\frac{1}{2}$ inch from fracture $=0.736$ inch. Fractured diameter $=0.745$ inch; flaw in surface.

598-1st spec.-Surface corrugated; Haw in fracture; least diameter $\frac{1}{2}$ inch from fracture $=0.775$ inch. Fractured diameter $=0.778$ inch.

2nd spec.-Flaw in fracture.

$600-1$ st spec.-Flaw in fracture.

2nd spec.-Flaw in fracture.

$601-1$ st spec.-Flaw in fracture.

2nd spec.-No flaw.

602-1st spec.-Slight corrugation 2 inches from fracture; least diameter at corrugation $=0.780$ inch; broke in fillet.

2nd spec. - Slight corrugation entire length of surface ; diameter $=0.775$ inch over whole length.

603-1st spec.-Flaw in centre of fracture; surface smooth.

2nd spec.-Slight corrugation at end opposite fracture; diameter at corrugation and at fracture $=0.782$ inch; flaw in centre of fracture.

604-1st spec.-Slight flaw.

2nd spec.-Flaw in fracture.

611-1st spec.-Surface badly corrugated; flaw in fracture; least diameter 1 inch from fracture $=0 \cdot 768$ inch. Fractured diameter $=0.775$ inch.

2nd spec.-Flaw in fracture.

612-1st spec.-Surface badly corrugated; fracture very ragged.

2nd spec.-Surface slightly corrugated; faw in fracturo.

634-1st spec.-Surface corrugated; fracture peculiar, showing two kinds of grains.

2nd spec.-Surface badly corrugated; section like its companion.

635-1st spec.--Surface slightly corrugated and seamy; flaw in fracture; least diameter inch from fracture $=0 \cdot 777$ inch. Fractured diameter $=0.785$ inch.

2nd spec.-Surface corrugated and seamy; least diameter 1 inch from fracture $=0.659$ inch. Fractured diameter $=0.750$ inch; flaw in fracture. 
636-1st spec--Surface roughened and showing fibre, but not corrugated; fracture humpy and spotted, peculiar.

2nd spec.-Surface corrugated, fracture like its companion.

637-1st spec. -No flaw.

2nd spec.-No Hlaw.

The order of standing of the soft charges, as deduced from Table 10, is given in Table 9 .

Table 9.-General Order of Soft Charges, Mechanical Test.

\begin{tabular}{c|c|c|c|c|c|c|c|c|c|c}
\hline 1 & 2 & 3 & 4 & 5 & 6 & 7 & 8 & 9 & 10 & 11 \\
\hline 634 & 601 & 602 & 600 & 612 & 636 & 603 & 596 & 611 & 635 & 598 \\
\hline
\end{tabular}

Order of Soft Charges in Elastio Limit.

\begin{tabular}{c|c|c|c|c|c|c|c|c|c|c}
\hline 1 & 2 & 3 & 4 & 5 & 6 & 7 & 8 & 9 & 10 & 11 \\
\hline 601 & 600 & 596 & 602 & 598 & 603 & 612 & 634 & 635 & 636 & 611 \\
\hline
\end{tabular}

Order of Sofit Charges in Ultimate Strength.

\begin{tabular}{c|c|c|c|c|c|c|c|c|c|c}
\hline 1 & 2 & 2 & 3 & 4 & 5 & 6 & 7 & 7 & 8 & 9 \\
\hline 601 & 602 & $63 \pm$ & 603 & 600 & 612 & 635 & 596 & 598 & 611 & 636 \\
\hline
\end{tabular}

Order of Soft Changes in Dectility.

\begin{tabular}{c|c|c|c|c|cc|c|c|c|c}
\hline 1 & 1 & 2 & 3 & 4 & 5 & 6 & 7 & 7 & 8 & 9 \\
\hline 634 & 636 & 611 & 612 & 635 & 602 & 596 & 601 & 603 & 600 & 598 \\
\hline
\end{tabular}

The two hard charges, Nos. 601 and 637, would stand, respectively, 637 first and 604 second; and, on an average, they would stand before all the soft steels.

Having thus given all the facts and conditions of the mechanical tests, some general conclusions may be drawn therefrom. An abstract of Professor Thurston's report is first presented.

"All of the steels are of too low a grade in carbon to take a temper or to harden well. They are, therefore, of the grades used for machinery steel, and for the various uses to which the 'mild' steels are adapted.

"As compared with the common steels, they exhibit a higher elast.c limit than the latter when of equal tenacity, and a not.bly 
greater elastic resilience or shock-resisting power when the effect of the shock is not serious enough to produce permanent change of form. In this respect their superiority amounts to from 10 to 15 per cent.

"They are not as ductile as the common steels with which we have had experience. Their higher elastic limit is accompanied by a lower degree of toughness. They are harder and rather less tough than the standard steels.

"For ordinary work, when they are not liable to excessive accidental strain, they are less liable to be given a change of form by loading than common steels. When liable to sudden and excessive shocks, they are more liable to break. If in such event they do not break, they will exhibit less distortion and deformation than ordinary steels of similar grade.

"Comparing these steels with common steels of similar temper, it would seem that these steels excel usually in strength, and in some cases are greatly superior in tenacity to the ordinary classes of steel.

"Some of these steels exhibit defects in structure, which may, I presume, be avoided by care and skill in manufacture; those free from these defects are fine-looking steels. The fractures are peculiar in appearance, and the whole behaviour of the metals is so decidedly peculiar that I am unable to express an opinion in regard to the extent and character of their applications as unqualifiedly as I would like."

The foregoing conclusions of Professor Thurston seem to follow fairly from the results given in the tables. It must be borne in mind, that, in arriving at these conclusions, he had no data except his own tests and the amounts of carbon in the several specimens.

In reviewing the data, it will be found that there are three grades of steel : 604 and 637 , which are low tool steels ; 596, 598, $600,601,602$, and 603 , which are rather hard structural steels; and $611,612,634,635$, and 636 , which are soft structural steels or "ingot irons."

The second lot or hard structural steels have the following average composition and average order of elastic limit, ultimate strengti, and ductility (see Table 9):

C. $0 \cdot 22$, Mn. $0 \cdot 638$, P. $0 \cdot 341$, Elas. limit No. $3 \frac{1}{2}$, Ult. strength No. 4, Duct. No. 7 .

The third lot or soft structural steels have the following average composition and physical properties:

C. $0 \cdot 118$, Mn. $0 \cdot 49$, P. $0 \cdot 272$, Elas. limit No. 9, Ult. strength No. 6, Ductility No. 2. 
When the percentage of hardening elements is great (that of silicon is so small in all the specimens that it need not be considered), the elastic limit is high, the ultimate strength rather high, and the ductility very low. When the percentage of hardening limits is small, the reverse is the case. The steels seem to follow this general law, although all the ingredients in each grade bear such a close relative proportion to each other, that the special effects of any one ingredient cannot be closely traced.

Some of the physical differences however cannot be explained by chemical analysis. For instance, the analyses of charges No. 604 and No. 637 differ only by a few hundredths of the various ingredients; but in tensile strength, within the elastic limit, No. 637 stands No. 1 on the list, while No. 604 is No. 4. The ultimate strength shows No. 637 to be No. 5, and No. 604 to be No. 13. In the chemical analysis the reason cannot be found why, of the following steels, No. 634 should head the list, No. 636 be intermediate, and No. 635 nearly at the bottom. No. 635 should be first, for it contains less phosphorus and more manganese than the other charges. It should also stand far ahead of No. 596, which contains $0 \cdot 13$ more phosphorus. The large proportion of manganese in charge No. 602 seems to have had but little influence on the physical properties of the metal. Its resilience should have been considerably increased. But, in this respect, charge No. 612, which contains but little more than one-third the quantity of this ingredient, stands nearly as well. The unsoundness of the tensional test-pieces is no doubt a prominent cause of these discrepancies; but it does not appear fully to account for them.

\section{Conclusions.}

1st. The above-mentioned discrepancies may be partly due to a lack of homogeneity, or to an uneven distribution of ingredients in steel which contains a large amount of phosphorus and of manganese.

2nd. The phosphoric steels are slightly stronger (elastic limit) than common steels having the same amount of carbon.

3rd. The most notable difference between the phosphoric steels and the common steels is the small comparative ductility of the former.

4th. From the Terrenoire experiments, referred to in the Appendix, another conclusion, important in this connection, may be drawn. Phosphoric steel must be well worked-largely reduced 
CHEMICAL AND PHYSICAL ANALYSES OF PHOSPHORIC STEEL. 241

in the rolls-in order to acquire either its maximum malleability or its maximum strength and ductility. The steels under consideration were too little worked to bring out the best results.

It is thus evident that the phosphoric steels are well adapted to uses where great strength under a statical load is required; but that they are not trustworthy, any more than steels rich in carbon, where they are subjected to severe sudden strains. 


\section{APPENDIX.}

\section{TERRENOIRE PHOSPHORIC (OPEN HEARTH) STEEL.}

\section{A Comparison of the Chemical ayd Physrcal Tests of pifferent Phos- PHoric SteEls with each other AND WITH those OF gOOD Bessemer RaIL Steel.}

Note.-The following compilation was made from various published results, by $M r$. L. G. Laureau.

Table A gives a comparicon between a good Bessemer rail and a phosphoric steel rail. The rails were placed hearl up, on supports 1 metre ( 3 feet $3 \frac{3}{8}$ inches) apart and successively loaded with weights, as per table.

Observations.-1st. Up to a point whish may accurately be called the elastic limit, the phosphoric steel behaves in every particular as well as the Bessemer.

2nd. Beyond the elastic limit deformation is greater in the phosphoric metal, and the ultimate resistance is slightly lower. The great difference in the percentares of carbon in the two steels should be noted in this connection. On the whole the result is satisfactory; the Railway Company's requirements that the rail shall stand a load of $44,100 \mathrm{lbs}$. without permauent set, and 66,150 lbs. before breaking, ne fully met.

Table B compared with Table A. shows how far, under the same load, the deflection and set of both steels decrease in 70-1b. as compared with 60-1b. rails.

$\mathrm{N}$.ither the Bessemer nor the phosphoric $70-1 \mathrm{~b}$. steel rails bear the present railway requirement, which is about $55,000 \mathrm{lbs}$. without permanent set. The tests recorded in Table $\mathbf{B}$ were made before the railway standard was raised; since then the Bessemer metal has been stiffened by a larger percentage of manganese, and the phosplroric steel has been brought to the present standard composition (P. $0 \cdot 22, \mathrm{Mn} .0 \cdot 80$ ).

A comparison of 'Tables $\mathbf{C}$ and $\mathbf{A}$ shows in detail, and Table $\mathbf{D}$ more compre. hensively scts forth, that largely increasing the manganese in phosphorio steel increases its stiffness; and that, although it does not sensibly raise the elastic limit, it dirninishes the amount of deformation beyoud it. The accompanying decrease of phosphorus, although slight, may have tended to reduce the stiffness.

Tables $\mathrm{E}, \mathrm{F}$, and $\mathrm{G}$ show the comparative results of drop tests made on the rails used in the preceding bending tests, and Table $I I$ sums up the effects of manganese under this lsind of test. The rails were placed head np on supports 3 feet $7 \frac{1}{2}$ inches apart; the falling weight was $661 \mathrm{lbs}$., first dropped from a lieight of 20 inches, and successively raised to a heiglt furnishing the stress expressed in foot-pounds in the tables. The Railway Company's demand is that the rail shall not break at or below a stress of 4000 foot-lbs. All the metal amply met the requirements.

The results brought out by the bending tests are fully sustained by the drop tests. They are substantially:-

1st. A similarity in the behaviour of the phosphoric and the Bessemer steels as far as the clastic limit.

2nd. Greater deformation in phosphoric than in Bessemer steel beyond the elastic limit.

3:d. Increase of stiffucss in the phosphoric metal, with an increase of mansanese. 
Table $J$ shows the tensile strength of bars and strips taken from different parts of Bessemer and phosphoric steel rails and plates.

Observations. - Ist. Within the elastic limit both metals behave very nearly alike; but the presence of phosphorus, associated with low carbon, reduces the ultimate resistance.

2nd. In the Bessemer steel the extra work received by the web in the rolls did not greatly change its physical properties. Rolling it down to plates, however, reduced the elastic limit and the ultimate strength, and increased the ductility.

3rd. In phosphoric steel, on the contrary, the extra work on the web, and especially the reduction into plates, largely increased the ultimate resistance as well as the ductility.

The important conclusion may be drawn from this, and from many similar experiments at Terrenoire, that phosphoric steel should be thoroughly worked; and that, especially when toughness is required, the product should be reduced from large ingots.

Table A.-Deflection and Set of 60-1b. Steel Rails under Statical Loade. 393-INCH SUPPORTS.

\begin{tabular}{|c|c|c|c|c|c|}
\hline \multirow{2}{*}{ Loads. } & \multicolumn{2}{|c|}{ Bessemer Steel. } & \multicolumn{2}{|c|}{ Phosphoric Steel. } & \multirow[b]{2}{*}{ Analyses. } \\
\hline & Deflection. & $\begin{array}{c}\text { Permanent } \\
\text { Set. }\end{array}$ & Deflection. & $\begin{array}{l}\text { Permanent } \\
\text { Set. }\end{array}$ & \\
\hline $\begin{array}{c}\text { 1bs. } \\
27,562 \\
38,587 \\
44,100 \\
55,125\end{array}$ & $\begin{array}{l}\text { Inch. } \\
0 \cdot 098 \\
0 \cdot 126 \\
0 \cdot 138 \\
0 \cdot 173\end{array}$ & $\begin{array}{l}\text { Inch. } \\
\ddot{.} \\
\ddot{0} \\
0 \cdot 008\end{array}$ & $\begin{array}{l}\text { Inch. } \\
0 \cdot 091 \\
0 \cdot 118 \\
0 \cdot 133 \\
0 \cdot 172\end{array}$ & $\begin{array}{l}\text { Inch. } \\
\ddot{.} \\
\ddot{0} \\
0 \ddot{0} 04\end{array}$ & $\begin{array}{l}\text { Bessemer Steel. } \\
\text { C. } 0.45 \text { to } 0.55 \text {. } \\
\text { Mn. } 0.15 \text { to } 0.25 \text {. } \\
\text { P. Traces to } 0.04 \text {. }\end{array}$ \\
\hline $\begin{array}{l}66,150 \\
77,175\end{array}$ & $\begin{array}{l}0 \cdot 326 \\
0 \cdot 642\end{array}$ & $\begin{array}{l}0 \cdot 126 \\
0 \cdot 394\end{array}$ & $\begin{array}{l}0 \cdot 936 \\
1 \cdot 523 \\
\end{array}$ & $\begin{array}{l}0 \cdot 736 \\
1 \cdot 240 \\
\end{array}$ & $\begin{array}{l}\text { Phosphoric Steel. } \\
\text { C. } 0 \cdot 15 \text { to } 0 \cdot 20 \text {. } \\
\text { Mn. } 0.25 \text { to } 0.95 \text {. }\end{array}$ \\
\hline $\left.\begin{array}{c}\text { Braking } \\
\text { load }\end{array}\right\}$ & \multicolumn{2}{|c|}{99,225 to 108,000} & \multicolumn{2}{|c|}{94,815 to 105,960} & P. 0.27 to 0.32 . \\
\hline
\end{tabular}

Table B.-Deflection and Set of 70-1b. Raths of smilar Steel (Table A). 39:-INCH SUIPORTS.

\begin{tabular}{|c|c|c|c|c|}
\hline \multirow{2}{*}{ Loads. } & \multicolumn{2}{|c|}{ Bessemer Steel. } & \multicolumn{2}{|c|}{ Phosphoric Steel. } \\
\hline & Deflection. & Permanent Set. & Deflection. & Permanent Set. \\
\hline lbs. & Inch. & Jnch. & Inch. & Inch. \\
\hline 27,562 & 0.055 & .. & $0 \cdot 059$ & .. \\
\hline 38,587 & 0.078 & .. & 0.086 & \\
\hline 44,100 & $0 \cdot 106$ & 0.004 & $0 \cdot 106$ & 0.004 \\
\hline 55,125 & $0 \cdot 129$ & 0.008 & 0.132 & 0.011 \\
\hline 66,150 & $0 \cdot 173$ & 0.019 & 0.232 & 0.078 \\
\hline 77,175 & $0 \cdot 326$ & 0.145 & $0 \cdot 665$ & 0.492 \\
\hline $\begin{array}{c}\text { Breaking } \\
\text { load. }\end{array}$ & \multicolumn{2}{|c|}{108,000 to 114,660} & \multicolumn{2}{|c|}{99,225 to 110,250} \\
\hline
\end{tabular}


Table C.-Deflection and Set of 60-lb. Rails, varying P. and Mn. 393 -INCH SUPPORTS.

\begin{tabular}{|c|c|c|c|c|c|}
\hline \multirow{2}{*}{ Loads. } & \multicolumn{2}{|c|}{ Charges 1,767 and 1,771 . } & \multicolumn{2}{|c|}{ Charges 1,769 and $1,773}$. & \multirow{3}{*}{$\begin{array}{l}\text { Analysis, Charges } \\
1,767 \text { and } 1,771 \text {. } \\
\text { C. } 0.17 \text { to } 0.22 \text {. } \\
\text { Mn. } 1.00 \text { to } 1.20 \text {. } \\
\text { P. } 0.25 \text { to } 0.27 \text {. } \\
\text { Si. } 0.01 \text { to } 0.06 \text {. }\end{array}$} \\
\hline & Deflection. & $\begin{array}{l}\text { Permanent } \\
\text { Set. }\end{array}$ & Deflection. & $\begin{array}{l}\text { Permanent } \\
\text { Set. }\end{array}$ & \\
\hline $\begin{array}{c}\text { lbs. } \\
27,562\end{array}$ & $\begin{array}{l}\text { Inch. } \\
0.070\end{array}$ & $\begin{array}{l}\text { Inch. } \\
\text {.. }\end{array}$ & $\begin{array}{l}\text { Inch. } \\
0 \cdot 073\end{array}$ & $\begin{array}{c}\text { Inch. } \\
. .\end{array}$ & \\
\hline 38,587 & 0.091 & .. & 0.091 & $\ddot{*}$ & \\
\hline 44,100 & $0 \cdot 106$ & $\because$ & $0 \cdot 109$ & $\because$ & Analysis. Charges \\
\hline 55,125 & $0 \cdot 138$ & 0.007 & $0 \cdot 141$ & 0.003 & 1,769 and 1,773 . \\
\hline $\begin{array}{l}66,150 \\
77,175\end{array}$ & $\begin{array}{l}0.370 \\
0.940\end{array}$ & $\begin{array}{l}0 \cdot 200 \\
0 \cdot 740\end{array}$ & $\begin{array}{l}0.495 \\
1 \cdot 330\end{array}$ & $\begin{array}{l}0 \cdot 326 \\
1 \cdot 122\end{array}$ & $\begin{array}{l}\text { C. } 0.17 \text { to } 0.22 \text {. } \\
\text { Yn. } 0.50 \text { to } 0.70 \text {. }\end{array}$ \\
\hline $\begin{array}{c}\text { Breaking } \\
\text { load }\end{array}$ & 94,815 & 05,960 & 94,815 & 105,960 & $\begin{array}{l}\text { P. } 0.28 \text { to } 0.31 \text {. } \\
\text { Si. } 0.01 \text { to } 0.06 \text {. }\end{array}$ \\
\hline
\end{tabular}

Tarle D.-Showing increased Stiffness under Statical Load, due to Mn. For details see Tables $A$ and $C$.

\begin{tabular}{|c|c|c|c|c|c|c|}
\hline \multirow{2}{*}{ Loads. } & \multicolumn{2}{|c|}{$\begin{array}{l}\text { Mn. } 1 \cdot 00 \text { to } 1 \cdot 20 \\
\text { P. } 0.25 \text { to } 0 \cdot 27 \text {. }\end{array}$} & \multicolumn{2}{|c|}{$\begin{array}{l}\text { Mn. } 0.50 \text { to } 0.70 . \\
\text { P. } 0.28 \text { to } 0.31 \text {. }\end{array}$} & \multicolumn{2}{|c|}{$\begin{array}{l}\text { Mrn. } 0.25 \text { to } 0 \cdot 35 \text {. } \\
\text { P. } 0.27 \text { to } 0.32 \text {. }\end{array}$} \\
\hline & Deflection. & $\begin{array}{c}\text { Permanent } \\
\text { Set. }\end{array}$ & Deflection. & $\begin{array}{l}\text { Permanent } \\
\text { Set. }\end{array}$ & Deflection. & $\begin{array}{l}\text { Permanent } \\
\text { Set. }\end{array}$ \\
\hline $\begin{array}{c}\text { lhs. } \\
66,150 \\
77,175\end{array}$ & $\begin{array}{l}\text { Inch. } \\
0.370 \\
0.940\end{array}$ & $\begin{array}{l}\text { Inch. } \\
0 \cdot 200 \\
0 \cdot 740\end{array}$ & $\begin{array}{c}\text { Inch. } \\
0.495 \\
1.330\end{array}$ & $\begin{array}{l}\text { Inch. } \\
0 \cdot 326 \\
1 \cdot 122\end{array}$ & $\begin{array}{l}\text { Inch. } \\
0.986 \\
1.523\end{array}$ & $\begin{array}{l}\text { Inch. } \\
0 \cdot 736 \\
1 \cdot 240\end{array}$ \\
\hline
\end{tabular}

Table E.-Deflection of 60-lb. Rails of Table A, under Blows.

\begin{tabular}{|c|c|c|}
\hline $\begin{array}{c}\text { Force of Blow in } \\
\text { Foot-lbs. }\end{array}$ & Bessemer Steel. & Plosphoric Steel. \\
\cline { 2 - 3 } & Deflection. & Deflection. \\
\hline & Inch. & Inch. \\
$\mathbf{1 , 0 8 4}$ & $0 \cdot 031$ & $0 \cdot 070$ \\
$\mathbf{1}, 620$ & $0 \cdot 062$ & $0 \cdot 144$ \\
$\mathbf{2}, 168$ & $0 \cdot 144$ & $0 \cdot 288$ \\
$\mathbf{3}, 252$ & $0 \cdot 295$ & $0 \cdot 472$ \\
4,336 & $0 \cdot 915$ & 0.917 \\
5,420 & $1 \cdot 307$ & $1 \cdot 338$ \\
6,504 & $1 \cdot 811$ \\
\hline Breaking stress & 8,124 to 9,214 & 7,592 to 8,124 \\
in foot-lbs. & & \\
\hline
\end{tabular}


OHEMICAL AND PHYSICAL ANALYSES OF PHOSPHORIO STEEL. 245

Table F.-Deflection of 70-1b. Ratls of Table B, under Blows.

\begin{tabular}{|c|c|c|}
\hline $\begin{array}{c}\text { Force of Blow in } \\
\text { Foot-1bs. }\end{array}$ & Bessemer Steel. & Phosphoric Steel. \\
\cline { 2 - 3 } & Deflection. & Deflection. \\
\hline 1,084 & $\begin{array}{c}\text { Inch. } \\
0.019\end{array}$ & $\begin{array}{c}\text { Inch. } \\
0.031\end{array}$ \\
1,620 & 0.028 & 0.051 \\
2,168 & 0.091 & 0.078 \\
3,252 & 0.118 & 0.165 \\
4,336 & 0.307 & 0.381 \\
5,420 & 0.551 & 0.669 \\
6,504 & 0.826 & 1.023 \\
\hline $\begin{array}{c}\text { Breaking stress } \\
\text { in foot-lbs. }\end{array}$ & 8,672 to 9,756 & 7,592 to 8,672 \\
\hline
\end{tabular}

Table G.-Deflection of 60-lb. Rans of Tabli C, under Blows.

\begin{tabular}{|c|c|c|}
\hline $\begin{array}{c}\text { Force of Blow in } \\
\text { Foot-lbs. }\end{array}$ & Charges $1,767 \&$ \& 1,771. & Charges $1,769 \&$ \& $1,773$. \\
\hline & Inch. & Deflection. \\
\hline 1,084 & 0.039 & Inch. \\
1,620 & 0.078 & 0.039 \\
2,168 & 0.165 & 0.099 \\
3,252 & 0.322 & 0.216 \\
4,336 & 0.551 & 0.393 \\
5,420 & 0.834 & 0.669 \\
6,504 & 1.102 & 0.994 \\
\hline $\begin{array}{c}\text { Breaking stress } \\
\text { in foot-lbs. }\end{array}$ & 6,504 to 9,756 & 9,756 and above. \\
\hline
\end{tabular}


Table H.--Showing increased Stiffness under Blows due to Mn. For details see Tables $\mathbf{A}$ and $\mathbf{C}$.

\begin{tabular}{|c|c|c|c|}
\hline \multirow{2}{*}{$\begin{array}{l}\text { Force of Blow in } \\
\text { Fout-lbs. }\end{array}$} & $\begin{array}{l}\text { Mn. } 1 \cdot 00 \text { to } 1 \cdot 20 \\
\text { P. } 0.25 \text { to } 0.27 \text {. }\end{array}$ & $\begin{array}{l}\text { Mn, } 0.50 \text { to } 0.70 \text {. } \\
\text { P. } 0.28 \text { to } 0.31 \text {. }\end{array}$ & $\begin{array}{l}\text { Mn. } 0.25 \text { to } 0.35 \text {. } \\
\text { P. } 0 \cdot 27 \text { to } 0.32 \text {. }\end{array}$ \\
\hline & Deflection. & Deflection. & Deflection. \\
\hline 4,336 & $\begin{array}{c}\text { Inch. } \\
0 \cdot 551\end{array}$ & $\begin{array}{l}\text { Inch. } \\
0.669\end{array}$ & $\begin{array}{l}\text { Inch. } \\
0 \cdot 917\end{array}$ \\
\hline 5,420 & 0.834 & 0.994 & $1 \cdot 338$ \\
\hline 6,504 & $1 \cdot 102$ & $1 \cdot 495$ & $1 \cdot 811$ \\
\hline
\end{tabular}

Table J.-Tensue Tests showing the effect of reduction on the Begsemer and Phosphoric Steels of Tarle A.

Length of test bars 4 inches.

\begin{tabular}{c|c|c|c}
\hline & Elastic Limit. & Breaking Load. & Elongation. \\
\hline $\begin{array}{c}\text { Bessemer Steel. } \\
\text { Test bars taken from head of rails }\end{array}$ & $24 \cdot 70$ & $49 \cdot 53$ & $8 \cdot 5$ \\
Test strips taken from web of rails . & $26 \cdot 03$ & $48 \cdot 13$ & $8 \cdot 5$ \\
Test strips taken from plates.. & $23 \cdot 81$ & $45 \cdot 59$ & $11 \cdot 2$ \\
Phosphoric Steel. & & & \\
Test bars taken from head of rails . & $24 \cdot 13$ & $33 \cdot 21$ & $11 \cdot 2$ \\
Test strips taken from web of rails . & $25 \cdot 40$ & $35 \cdot 43$ & $12 \cdot 7$ \\
Test strips taken from plates. & $21 \cdot 27$ & 36.32 & $21 \cdot 3$ \\
\hline
\end{tabular}

